\title{
Visible Absorption Spectra of the 4 f Electron Transitions of Neodymium, Praseodymium, Holmium and Erbium Complexes with Fleroxacin and Their Analytical Application
}

\author{
Naixing WANG, ${ }^{*}$ Wei JIANG, * Xiuqin XU,** Zhikun SI,* Haitao BAI,* and Cong TIAN* \\ *Department of Chemistry, Shandong University, Jinan, 250100, China \\ **Hospital of Shandong University, Jinan, 250100, China
}

\begin{abstract}
The absorption spectra of the $4 \mathrm{f}$ electron transitions of neodymium, praseodymium, holmium and erbium complexes with fleroxacin in the presence of cetylpyridinium chloride were studied by normal and derivative spectrophotometry. Their molar absorptivity at the maximum absorption bands are about 5.3 (at $571 \mathrm{~nm}$ ) times greater for neodymium, 2.8 (at 483 $\mathrm{nm}$ ) times greater for praseodymium, 12.6 (at $448.5 \mathrm{~nm}$ ) times greater for holmium and 9.7 (at $519 \mathrm{~nm}$ ) times greater for erbium than those in the absence of complexing agents. The second-derivative spectrum is used both to eliminate the interference from other rare earths and to improve the sensitivity. Beer's law is obeyed from $3.0-70 \mu \mathrm{g} \mathrm{m} \mathrm{l}^{-1}$ for neodymium and holmium, from $6.0-70 \mu \mathrm{g} \mathrm{ml}^{-1}$ for erbium, and from $12.0-70 \mu \mathrm{g} \mathrm{ml}^{-1}$ for praseodymium. The relative standard deviations are $1.9 \%$ and $1.5 \%$ for $7.5 \mu \mathrm{g} \mathrm{ml}^{-1}$ of neodymium and holmium, and $2.1 \%$ and $1.6 \%$ for $15.0 \mu \mathrm{g} \mathrm{ml} \mathrm{m}^{-1}$ of praseodymium and erbium, respectively. Their detection limits (signal-to-noise ratio $=2$ ) are $3.2 \mu \mathrm{g} \mathrm{ml}^{-1}, 1.3 \mu \mathrm{g} \mathrm{ml}^{-1}$, $1.1 \mu \mathrm{g} \mathrm{ml}^{-1}$ and $2.5 \mu \mathrm{g} \mathrm{ml}^{-1}$ for praseodymium, neodymium, holmium and erbium, respectively. A new system for the simultaneous determinations of the praseodymium, neodymium, holmium and erbium in rare earth mixtures with good accuracy and selectivity is proposed.
\end{abstract}

(Received November 26, 2001; Accepted February 18, 2002)

The absorption spectra of rare earth ions consisting of arrow bands due to electronic transitions within the $\mathrm{f}^{n}$ configuration, are affected only slightly by changes in the environment of the metal ion. However, if the strength of the ionic field surrounding the rare earth ions is sufficient to penetrate the shielding of the outer electrons of the ions, some absorption bands may be shifted in wavelength and enhanced in sensitivity. Certain chelating groups, notably the $\beta$-diketones and 8quinolines, are capable of overcoming this difficulty through the formation of an inner-complex compound. These have been used in the determination of one or two REES in mixtures. ${ }^{1-8}$

Fleroxacin

(1-fluoroethyl-6,8-difluoro-7-(4-methyl-1piperazinyl)-4-oxo-1,4-dihydro-3-quinoline carboxylic acid) is a fluorinated quinoline antibiotic medicine, which has not been reported as a reagent for the spectrophotometric determination of rare earth elements. In this work, the spectral characteristics of the $4 \mathrm{f}$ electron transitions of neodymium, praseodymium, holmium and erbium complexes with Fleroxacin in the presence of CPC were reported. A rapid, selective method for the second-derivative spectrophotometric determination of four components in mixed rare earths is described.

\section{Experimental}

Apparatus

A Shimadzu UV-240 spectrophotometer with an OP1-2 spectral processing attachment, which generates the derivative digitally, and $3.0-\mathrm{cm}$ cells were used. The $\mathrm{pH}$ values of the

$\doteqdot$ To whom correspondence should be addressed. solutions were measured with a pHs-2 meter (Analytical Apparatus Plant, Shanghai, China).

\section{Reagents and chemicals}

A $5.0 \times 10^{-2} \mathrm{~mol} \mathrm{dm}^{-3}$ aqueous solution of Fleroxacin (FLX, Delicacy Chemicals Ltd., Zhejiang Taizhou, China) was prepared by dissolving 1.127 g FLX of $99.85 \%$ purity in $100 \mathrm{ml}$ with distilled water. Stock lanthanide solutions $\left(5.0 \times 10^{-2} \mathrm{~mol}\right.$ $\mathrm{dm}^{-3}$ ) were prepared by dissolving an appropriate amount of the oxides with $>99.99 \%$ purity (Johnson Matthey, Royston, Hertfordshire, UK) in $5.0 \mathrm{ml}$ hydrochloric acid $(1+1)$; working solutions were prepared by dilution with water. A standard solution of cetylpyridinium chloride $\left(\mathrm{CPC}, 5.0 \times 10^{-2} \mathrm{~mol} \mathrm{dm}^{-3}\right)$ was prepared by dissolving $4.475 \mathrm{~g}$ of CPC (Fluka) in $250 \mathrm{ml}$ of water. The solution cetyltrimethylammonium bromide $\left(\right.$ CTMAB, $2.0 \times 10^{-2} \mathrm{~mol} \mathrm{dm}^{-3}$ ) was prepared by dissolving $0.729 \mathrm{~g}$ of CTMAB (Shanghai Chemical Reagent Plant, Shanghai, China) in $100 \mathrm{ml}$ of water. A solution of octylphenol poly(ethyleneglycol)ether (TX-100, $5.0 \% \mathrm{v} / \mathrm{v})$ was prepared by dissolving $5.0 \mathrm{ml}$ of TX-100 (Rohm and Haas, Philadelphia, PA, USA) in $100 \mathrm{ml}$ of water. A solution of dodecylbenzenesulfonic acid sodium salt (DBS, $2.0 \times 10^{-2} \mathrm{~mol}$ $\mathrm{dm}^{-3}$ ) was prepared by dissolving $1.742 \mathrm{~g}$ of DBS (Shanghai Chemical Reagent Plant, Shanghai, China) in $250 \mathrm{ml}$ of distilled water. A solution of sodium dodecylsulfonate (SDS, $2.0 \times 10^{-2}$ mol $\mathrm{dm}^{-3}$ ) was prepared by dissolving $1.442 \mathrm{~g}$ of SDS (Shanghai Chemical Reagent Plant, Shanghai, China) in $250 \mathrm{ml}$ of distilled water. A buffer solution ( $\mathrm{pH} 9.25$ ) was prepared by mixing $100 \mathrm{ml}$ of $1.0 \mathrm{~mol} \mathrm{dm}^{-3}$ ammonia and $100 \mathrm{ml}$ of $1.0 \mathrm{~mol}$ $\mathrm{dm}^{-3}$ ammonium chloride solutions. 


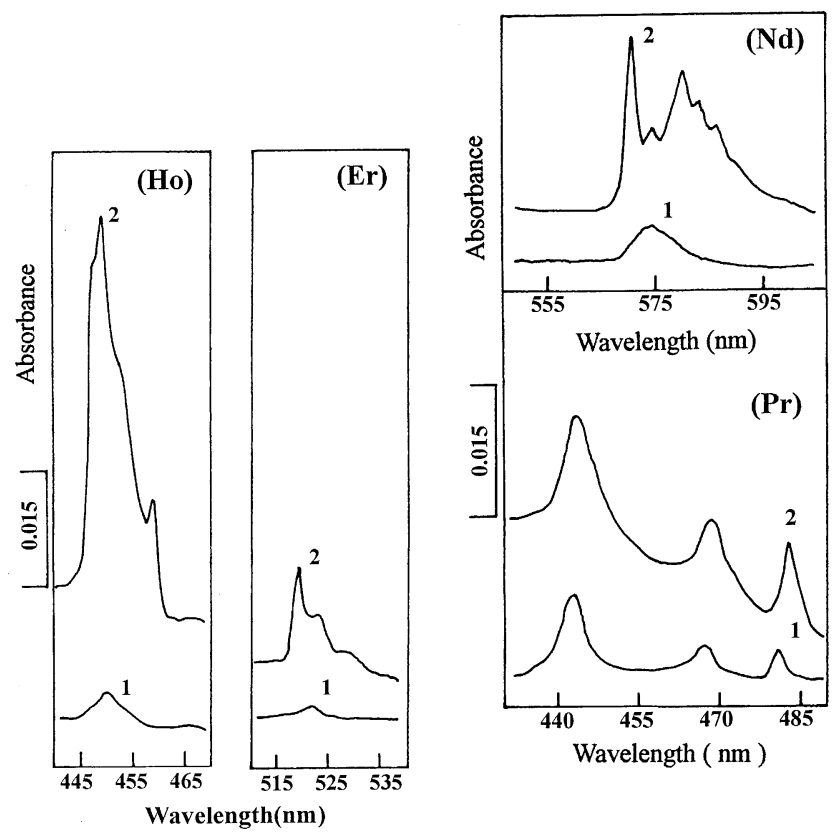

Fig. 1 Absorption spectra of lanthanide ions and complexes. $\left[\mathrm{Nd}^{3+}\right]=\left[\mathrm{Ho}^{3+}\right]=\left[\mathrm{Er}^{3+}\right]=2.5 \times 10^{-4} \mathrm{~mol} \mathrm{dm}^{-3} ;\left[\mathrm{Pr}^{3+}\right]=3.5 \times 10^{-4} \mathrm{~mol}$ $\mathrm{dm}^{-3} ;[\mathrm{FLX}]=5.0 \times 10^{-3} \mathrm{~mol} \mathrm{dm}^{-3} ;[\mathrm{CPC}]=5.0 \times 10^{-3} \mathrm{~mol} \mathrm{dm}^{-3} ; \mathrm{pH}$ $=9.25 ; 3.0-\mathrm{cm}$ cells. $1, \mathrm{LnCl}_{3}(\mathrm{pH}=5.6)$, water as reference; 2 , $\mathrm{Ln}^{3+}$-FLX-CPC, reagent blank as reference.

\section{General procedure}

After a known volume of a lanthanide solution was transferred into a $10 \mathrm{ml}$ calibrated flask, $1.0 \mathrm{ml}$ of $0.05 \mathrm{~mol} \mathrm{dm}^{-3}$ FLX, 1.0 $\mathrm{ml}$ of $0.05 \mathrm{~mol} \mathrm{dm}^{-3} \mathrm{CPC}$ and $2.0 \mathrm{ml} \mathrm{pH} 9.25$ of buffer solutions were added and mixed. The absorption spectra (or second derivative spectra) were recorded against a reagent blank using $3.0-\mathrm{cm}$ cells. The absorbance (or derivative absorption intensity) was measured.

\section{Analysis of reference material}

A $10 \mathrm{ml}(1+1)$ hydrochloric acid solution containing a mixed rare earth sample (approximately $0.5 \mathrm{~g}$ reference material, from Baotou Rare Earth Academy, China) was placed in a beaker, and the solution was evaporated to near dryness on a waterbath. The residue was dissolved in a $100 \mathrm{ml}$ volumetric flask with distilled water. Then, an appropriate amount of this solution (parallel five aliquots) was transferred into a $10 \mathrm{ml}$ volumetric flask, $3.0 \mathrm{ml}$ of $0.05 \mathrm{~mol} \mathrm{dm}^{-3}$ FLX, $1.0 \mathrm{ml}$ of 0.05 mol dm ${ }^{-3} \mathrm{CPC}$ and $2.0 \mathrm{ml} \mathrm{pH} 9.25$ of buffer solutions were added; the solution was then diluted to volume with distilled water and mixed. The second-derivative spectrum was recorded against a reagent blank, using $3.0 \mathrm{~cm}$ cells in $590-430 \mathrm{~nm}$ with $\Delta \lambda=1.0 \mathrm{~nm}$, band pass $=1.0 \mathrm{~nm}$ and scan rate $=20 \mathrm{~nm} \mathrm{~min}{ }^{-1}$. The positive peak-to-negative peak amplitudes were measured between 570(+) - 568(-) nm for neodymium, 478(+) - 481(-) $\mathrm{nm}$ for praseodymium, 443(+) - 445(-) $\mathrm{nm}$ for holmium and 514.5(+) - 516(-) nm for erbium, respectively.

\section{Results and Discussion}

\section{Spectral characteristics}

In the $\mathrm{Ln}^{3+}$-FLX-CPC system, as we know, only neodymium, praseodymium, holmium and erbium exhibit strong $4 \mathrm{f}$ electron transitions peaks. These transitions from the ground-state ${ }^{4} \mathbf{I}_{9 / 2}$

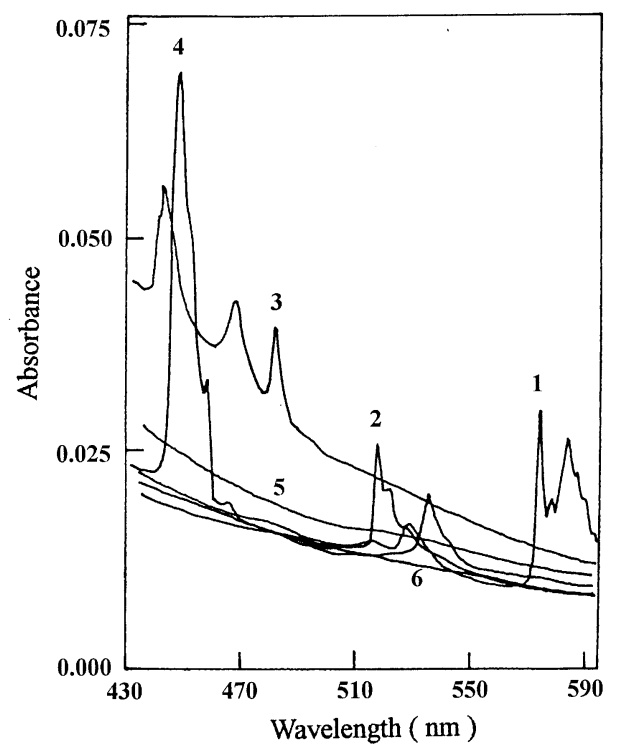

Fig. 2 Absorption spectra of lanthanide complexes. 1, Nd; 2, Er; 3, Pr; 4, Ho; 5, La; 6, Y. $[\mathrm{La}]=[\mathrm{Y}]=2.5 \times 10^{-4} \mathrm{~mol} \mathrm{dm}^{-3}$. Other conditions as in Fig. 1, curve 2.

of neodymium ion to the ${ }^{2} \mathrm{G}_{7 / 2},{ }^{4} \mathrm{G}_{5 / 2}$ excited states, the groundstate ${ }^{3} \mathrm{H}_{4}$ of praseodymium ion to the ${ }^{3} \mathrm{P}_{2},{ }^{1} \mathrm{I}_{6}+{ }^{3} \mathrm{P}_{1}$ and ${ }^{3} \mathrm{P}_{0}$ excited states, the ground-state ${ }^{5} \mathrm{I}_{8}$ of holmium ion to the ${ }^{5} \mathrm{G}_{6}$ excited state and the ground-state ${ }^{4} \mathrm{I}_{15 / 2}$ of erbium ion to the ${ }^{2} \mathrm{H}_{11 / 2}$ excited state give rise to narrow, relatively intense bands. The absorption spectra of aqueous solutions containing neodymium, praseodymium, holmium and erbium ions and an excess of FLX and CPC are shown in Fig. 1, from which it can be concluded that the absorbance in the absorption maximum for the neodymium complex it is 5.3 (at $571 \mathrm{~nm}$ ) times greater than that of chloride; for the praseodymium complex it is 2.8 (at $483 \mathrm{~nm}$ ) times greater than that of chloride; for the holmium complex it is 12.6 (at $448.5 \mathrm{~nm}$ ) times greater than that of chloride and for the erbium complex it is 9.7 (at $519 \mathrm{~nm}$ ) times greater than those of the corresponding chloride. The changes in the intensity and shape for the complexes can be explained as being due to the action of an increased co-ordination field in the ligand (or environment) surrounding the rare earth ions.

The influence of various surfactants on the absorption spectra of the complexes was studied in this system. The experimental results showed that solutions of the anionic surfactants DBS and SDS with FLX at $\mathrm{pH} 9.2$ brought about precipitation or turbidity; the non-ionic surfactant TX-100 only brought about a small increase in the absorption intensity of the complexes. The cationic surfactants $\mathrm{CPC}$ and $\mathrm{CTMAB}$ caused an enhancement of the absorption intensity of the complexes. In order to find the optimum conditions and analytical characteristics of the system, CPC was introduced to the system for further experiments.

Figure 2 shows that the interference of the background absorption of complexes must be eliminated to allow the determination of neodymium, praseodymium, holmium and erbium in a mixed system. A chemical method is not possible, whereas the use of the derivative spectra is not only selective and simple, but also improves the sensitivity due to the sharp absorption bands of the complexes.

We investigated the 1 st -4 th derivative spectra of different lanthanide complexes and variable measuring parameters of the instrument. It was found that the optimum conditions for 


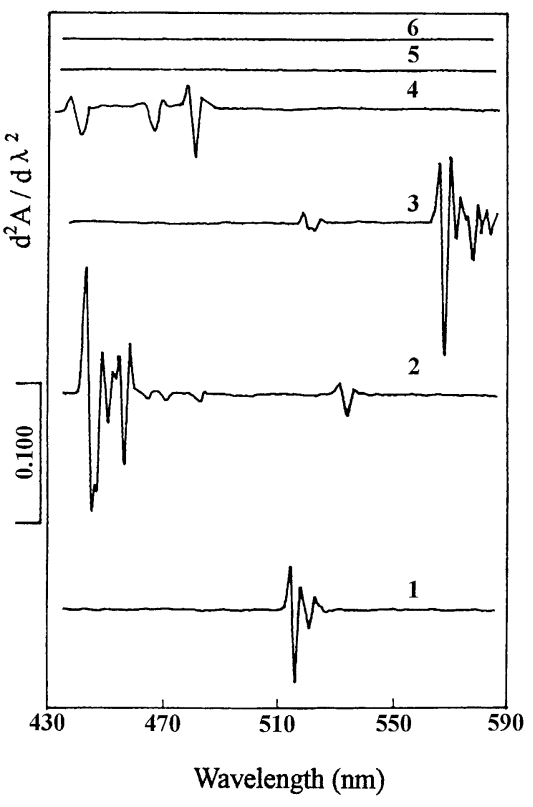

Fig. 3 Second-derivative absorption spectra of the complexes. $\Delta \lambda$ $=1.0 \mathrm{~nm}$, band pass $=1.0 \mathrm{~nm}$, scan rate $=20 \mathrm{~nm} \mathrm{~min}{ }^{-1} .1, \mathrm{Er} ; 2$, Ho; 3, Nd; 4, Pr; 5, La; 6, Y. Other conditions as in Fig. 2.

neodymium, praseodymium, holmium and erbium is to use the second-derivative spectrum with $\Delta \lambda=1.0 \mathrm{~nm}$, band pass $=1.0$ $\mathrm{nm}$ and scan rate $=20 \mathrm{~nm} \mathrm{~min}{ }^{-1}$. Figure 3 shows the secondderivative spectra of the representative lanthanide complexes. It is obvious that the optimal analytical signals at $478(+) \mathrm{nm}$ and $481(+) \mathrm{nm}$ for praseodymium; at $570(+) \mathrm{nm}$ and $568(-) \mathrm{nm}$ for neodymium; at 443(+) nm and 445(-) nm for holmium and at 514.5(+) $\mathrm{nm}$ and 516(-) $\mathrm{nm}$ for erbium, respectively. The other lanthanide does not have second-derivative absorption bands corresponding to the $4 \mathrm{f}$ electron transitions in this wavelength range, which suggested that the determination of neodymium, praseodymium, holmium and erbium in the presence of the other rare earths should be possible.

\section{Optimization of reaction conditions}

The influence of the $\mathrm{pH}$ and the amounts of various reagents used on the absorption intensity of complexes in this system were studied with neodymium as a representation (see Figs. 4 6). The results (the optimum range) for other elements (Pr, Ho, Er) are similar to that of neodymium. In the $\mathrm{pH}$ range $8.2-9.7$, the absorption maximum of the complexes was observed. A buffer solution of $\mathrm{pH} 9.25$ was chosen in subsequent experiments

The influence of the FLX concentrations on the absorption intensity of complexes at fixed concentrations of $\mathrm{Ln}^{3+}(\mathrm{Nd}, \mathrm{Pr}$, Ho, Er) was studied. The absorption intensity of complexes increased with an increase in the FLX concentrations, and tended to be constant, reaching the maximum when the FLX concentrations was greater than $1.7 \times 10^{-3} \mathrm{~mol} \mathrm{dm}^{-3}$. Thus, the amount of FLX used in the determination was always at least 18-times that necessary for the sum of the lanthanides.

The influence of the CPC concentrations was also tested. The results showed that the maximum absorption intensity of the complexes was only observed at a CPC concentration higher than $7.5 \times 10^{-4} \mathrm{~mol} \mathrm{dm}^{-3}$. The absorption was maximum and stable over wide ranges $\left(7.5 \times 10^{-4}-2.0 \times 10^{-2} \mathrm{~mol} \mathrm{dm}^{-3}\right)$ of the CPC concentrations. A concentration of $5.0 \times 10^{-3} \mathrm{~mol} \mathrm{dm}^{-3}$ of $\mathrm{CPC}$ was chosen for the determination.

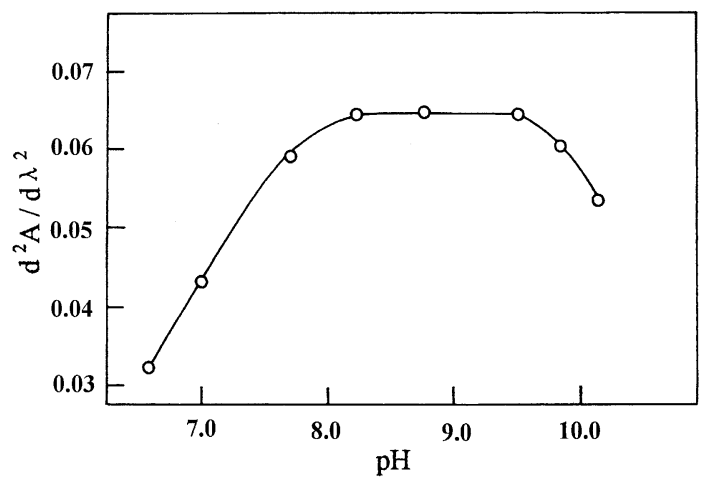

Fig. 4 Effect of the $\mathrm{pH}$ on the derivative absorption of complex. $\left[\mathrm{Nd}^{3+}\right]=1.0 \times 10^{-4} \mathrm{~mol} \mathrm{dm}{ }^{-3} ;[\mathrm{FLX}]=5.0 \times 10^{-3} \mathrm{~mol} \mathrm{dm}^{-3} ;[\mathrm{CPC}]=$ $5.0 \times 10^{-3} \mathrm{~mol} \mathrm{dm}^{-3} ; \Delta \lambda=1.0 \mathrm{~nm}$, band pass $=1.0 \mathrm{~nm}$, scan rate $=20$ $\mathrm{nm} \mathrm{min}^{-1}$. $3.0-\mathrm{cm}$ cells, reagent blank as reference. The peak-totrough amplitude is at $570(+)-568(-) \mathrm{nm}$.

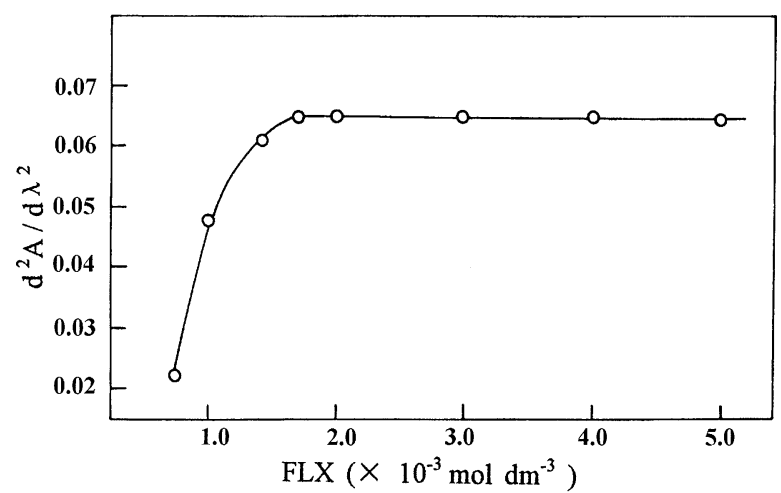

Fig. 5 Effect of FLX on the derivative absorption of complex. $\left[\mathrm{Nd}^{3+}\right]=1.0 \times 10^{-4} \mathrm{~mol} \mathrm{dm}^{-3} ;[\mathrm{CPC}]=5.0 \times 10^{-3} \mathrm{~mol} \mathrm{dm}^{-3} ; \mathrm{pH}=$ $9.25, \Delta \lambda=1.0 \mathrm{~nm}$, band pass $=1.0 \mathrm{~nm}$, scan rate $=20 \mathrm{~nm} \mathrm{~min}^{-1} .3 .0$ $\mathrm{cm}$ cells, reagent blank as a reference. The peak-to-trough amplitude is at $570(+)-568(-) \mathrm{nm}$.

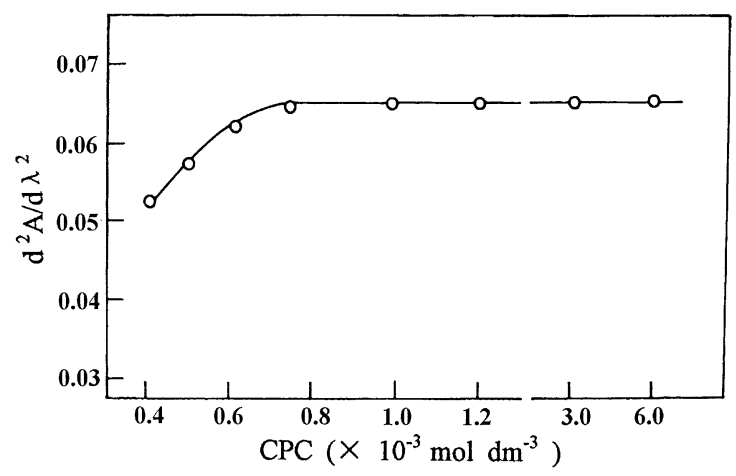

Fig. 6 Effect of $\mathrm{CPC}$ on the derivative absorption of the complex. $\left[\mathrm{Nd}^{3+}\right]=1.0 \times 10^{-4} \mathrm{~mol} \mathrm{dm}^{-3} ;[\mathrm{FLX}]=5.0 \times 10^{-3} \mathrm{~mol} \mathrm{dm}^{-3} ; \mathrm{pH}=$ $9.25, \Delta \lambda=1.0 \mathrm{~nm}$, band pass $=1.0 \mathrm{~nm}$, scan rate $=20 \mathrm{~nm} \mathrm{~min}^{-1} .3 .0$ $\mathrm{cm}$ cells, reagent blank as a reference. The peak-to-trough amplitude is at $570(+)-568(-) \mathrm{nm}$.

The complexes formed at once and the derivative absorption intensity was stable for at least $48 \mathrm{~h}$

\section{Beer's law, precision and detection limits}

Using the optimum instrument parameters and reaction 
Table 1 Compositions of synthetic samples $\left(\mathrm{Ln}^{3+}, \mu \mathrm{g} \mathrm{ml} \mathrm{m}^{-1}\right)$ and analytical results

\begin{tabular}{|c|c|c|c|c|c|c|c|c|}
\hline \multirow{2}{*}{ Present } & \multicolumn{4}{|c|}{ Found $^{\mathrm{a}}$} & \multicolumn{4}{|c|}{ RSD, ${ }^{\text {b } \%}$} \\
\hline & $\operatorname{Pr}$ & $\mathrm{Nd}$ & Но & $\mathrm{Er}$ & $\operatorname{Pr}$ & $\mathrm{Nd}$ & Но & $\mathrm{Er}$ \\
\hline $\begin{array}{l}\text { La } 140.0, \mathrm{Ce}(\mathrm{IV}) 350.0, \operatorname{Pr} 70, \mathrm{Nd} 108, \mathrm{Sm} 11.5, \mathrm{Eu} 9.1, \mathrm{Gd} 15.0, \\
\text { Ho } 15.0, \mathrm{Er} 20.0, \mathrm{Y} 10.0\end{array}$ & 68.5 & 110.0 & 14.6 & 20.6 & 1.9 & 1.6 & 2.1 & 1.9 \\
\hline $\begin{array}{l}\mathrm{La} 8.0, \mathrm{Ce}(\mathrm{IV}) 15.0, \operatorname{Pr} 30.0, \mathrm{Nd} 20.0, \mathrm{Sm} 15.0, \mathrm{Eu} 15.0, \mathrm{Gd} 50.0, \\
\text { Ho } 30.0, \mathrm{Er} 30.0, \mathrm{Y} 400\end{array}$ & 29.1 & 19.7 & 29.4 & 30.8 & 2.1 & 1.8 & 1.9 & 2.0 \\
\hline
\end{tabular}

a. Mean of five determinations. b. RSD $=$ relative standard deviation $(n=5)$.

Table 2 Analytical results of the reference material (oxides, $\mu \mathrm{g} \mathrm{ml}^{-1}$ )

\begin{tabular}{|c|c|c|c|c|c|c|c|c|c|c|}
\hline \multirow{2}{*}{ Present } & \multicolumn{2}{|c|}{ Added } & \multicolumn{4}{|c|}{ Found $^{\mathrm{a}}$} & \multicolumn{4}{|c|}{ RSD,,$\%$} \\
\hline & Ho & Er & $\operatorname{Pr}$ & $\mathrm{Nd}$ & Нo & $\mathrm{Er}$ & $\operatorname{Pr}$ & $\mathrm{Nd}$ & Ho & Er \\
\hline La 58.94, Ce(IV) 256.40, Y 0.17, Nd 61.88, Sm 7.89, Eu & 7.5 & 12.5 & 23.42 & 61.34 & 7.67 & 12.75 & 2.3 & 1.5 & 2.1 & 2.3 \\
\hline 0.99, Gd 1.80, Yb 0.066, Dy 0.32, Tb 0.11, Ho 0.082, Er & 15.0 & 25.0 & & & 15.18 & 25.28 & & & 1.1 & 1.8 \\
\hline $0.084, \operatorname{Pr} 23.84, \operatorname{Tm} 0.017, \mathrm{Lu} 0.0034$ & 20.0 & 30.0 & & & 20.17 & 30.39 & & & 0.8 & 1.2 \\
\hline
\end{tabular}

a. Mean of five determinations. b. RSD $=$ relative standard deviation $(n=5)$.

conditions established above, the calibration graphs were linear over the $3.0-70 \mu \mathrm{g} \mathrm{ml}^{-1}$ of neodymium and holmium, $6.0-70$ $\mu \mathrm{g} \mathrm{ml}^{-1}$ of erbium and $12.0-70 \mu \mathrm{g} \mathrm{ml}^{-1}$ of praseodymium (in the final solution). The equations obtained by the least-squares method:

$$
\begin{aligned}
& d^{2} A / d \lambda^{2}=0.006+0.001483 C^{\mathrm{Pr}}, r=0.9991(n=5), \\
& d^{2} A / d \lambda^{2}=0.0004+0.003938 C^{\mathrm{Nd}}, r=0.9999(n=5), \\
& d^{2} A / d \lambda^{2}=0.008+0.004245 C^{\mathrm{Ho}}, r=0.9995(n=5), \\
& d^{2} A / d \lambda^{2}=0.001+0.002092 C^{\mathrm{Er}}, r=0.9993(n=5),
\end{aligned}
$$

where $C$ is the concentration in units of $\mu \mathrm{g} \mathrm{ml}^{-1}$ and $r$ is a correlation coefficient. The relative standard deviations of the method studied for seven analyses of $7.5 \mu \mathrm{g} \mathrm{ml}^{-1}$ of neodymium and holmium, $15.0 \mu \mathrm{g} \mathrm{ml}^{-1}$ of praseodymium and erbium were $1.9 \%, 1.5 \%, 2.1 \%$ and $1.6 \%$, respectively. The detection limits (signal-to-noise ratio $=2$ ) were $1.3 \mu \mathrm{g} \mathrm{ml}^{-1}$ for neodymium, 1.1 $\mu \mathrm{g} \mathrm{ml}^{-1}$ for holmium, $3.2 \mu \mathrm{g} \mathrm{ml}^{-1}$ for praseodymium and $2.5 \mu \mathrm{g}$ $\mathrm{ml}^{-1}$ for erbium.

\section{Analytical application}

To prove the utility of the method, the results obtained for two synthetic samples (prepared based on the relative contents of rare earth oxides in the earth's crust ${ }^{9}$ ) are given in Table 1.

In addition, a reference material (from Baotou Rare Earth Academy, China) was also analyzed for neodymium and praseodymium. The obtained results are given in Table 2 . The reference material was not usable for holmium and erbium due to the low detection limits of the method. Hence, the applicability of the procedure for the determination of holmium and erbium in a reference material was tested by adding known amounts of holmium and erbium prior to dissolution of reference material. These results are also given in Table 2, from which it can be seen that the accuracy and precision of the method are satisfactory.

\section{References}

1. N. X. Wang, Q. C. Wu, J. B. Shi, and P. Qi, Mikrochim. Acta, 1993, 110, 119.

2. N. X. Wang, Z. K. Si, and W. Jiang, Anal. Lett., 1996, 29, 2191.

3. N. X. Wang, Z. K. Si, W. Jiang, and Z. C. Qi, Analyst, 1996, 121, 1317.

4. P. Qi, G. Y. Du, X. Z. Ren, L. Wang, W. Jiang, and N. X. Wang, J. Indian Chem. Soc., 1999, 1, 59.

5. N. X. Wang, W. A. Liang, and Z. Z. Zhang, Analyst, 1992, 12, 1963.

6. J. W. Kang, R. Y. Chen, and G. B. Bei, Acta Chim. Sin., 1984, 42, 921 .

7. J. Z. Gao, J. W. Kang, and G. B. Bei, Kexue Tongbao, 1979, 24, 1119.

8. N. X. Wang, Z. K. Si, and W. Jiang, Spectrochim. Acta, 1997, 53, 829

9. Y. E. Zeng, J. K. Cheng, and Q. Y. Luo, "Analytical Chemistry of Rare Earth Elements", 1981, Science Press, Beijing, Parts 1, 6. 